\title{
Analysis of boundary conditions in design circuits influence on the shaft line operating state
}

\author{
Alexei Khalyavkin ${ }^{1}$, Sergey Makeev ${ }^{2}$, Ali Salamekh ${ }^{1}$, and Aleksandra Ivanovskaya ${ }^{3, *}$ \\ ${ }^{1}$ Caspian Institute of sea and river transport named after General Admiral F. M. Apraksin - the branch \\ of the "VGAVT», 414000, Astrakhan, Russia \\ ${ }^{2}$ The Siberian State Automobile and Highway University, 644080, Omsk, Russia \\ ${ }^{3}$ Kerch State Maritime Technological University, 298309, Kerch, Russia
}

\begin{abstract}
The work investigates the bearing piece boundary conditions influence on the shaft line operating state, with respect to elastic properties of stern-tube bearings. It is noted that the shaft line is a part of the ship's power plant and it is a shaft system, located on the same axis. Performance criterion is the deflection of the concentrated load in the design scheme's action point, modeling the propeller's weight, bearing parts reactions and the natural frequency of linear lateral oscillations. The design scheme itself is a beam, resting on two elastic supports with a $\mathrm{k}$ stiffness factor, with concentrated load acting on the one end and three variants of the boundary conditions: pinched, hinged and sliding supports on another one. The results of calculations are given for different boundary conditions and the stiffness factors of elastic supports. The diagram of natural frequencies of linear lateral oscillations of ship`s shafting line is presented.
\end{abstract}

\section{Introduction}

Shaft line is a part of the ship's power plant and it is a shaft system, located on the same axis. It is designed to transmit torsion moment from the engine to the ship's propeller and the axial force perception from propeller to the ship's hull. There are a number of constant, variable and random loads acting on the ship's shaft line while in operation $[1,2]$. Loads arise from propeller's, engine's sides and in case of shafting line itself and its auxiliary mechanisms operating conditions failure. There were cases when the shafting line increased vibration caused cracks in the ship's aft part elements [3]. Therefore, the uninterrupted and reliable shaft line operation is an actual problem nowadays. It can be proved by the large number of publications worldwide [4-10].

In the shaft lines design, static and dynamic calculations are performed to determine deformations and stresses from bending in sections, loads on its supports, and determine the main parameters of torsion, longitudinal and transverse vibrations. In the static calculations the shaft line in the design scheme is considered as a beam, that rests on hinged supports and loaded with a distributed load. The distributed load simulates the entire shaft line and

* Corresponding author: invkerch@yandex.ru 
can be either constant or step-variable along the length. There is a concentrated load, that simulates the propeller's weight at one end of the beam, pinched supporting pier on another one. In many works $[3,4,11-13]$ related to the shaft line calculus, it is attempted to get away from the standard design scheme and resort to the necessary changes:

- pivot bearings, modeling stern tube bearings are replaced with elastic bearings or an elastic base (Winkler's model);

- the pinched support at the beam`s end is replaced by a hinged-fixed support;

- when calculating a beam on elastic supports, the 5 moments equation is used;

- when calculating transverse vibrations, only the stern part of the ship is taken into account, since it is the most loaded part of ship's shaft line and has the lowest natural frequency. The propeller shaft section includes the propeller, the propeller shaft console, the stern tube bearing, the propeller shaft nose or part of the intermediate shaft (depending on the shafting design).

\section{Materials and methods}

For the boundary conditions influence assessment, with the elastic properties of stern tube bearings taken into account, let us consider the shafting line design schemes, shown in Figure 1.

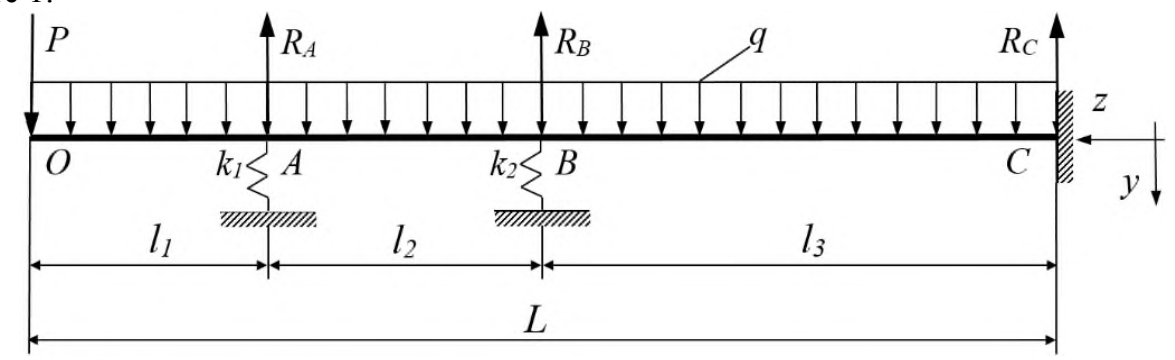

a) design model with the pinched support at the beam's end.

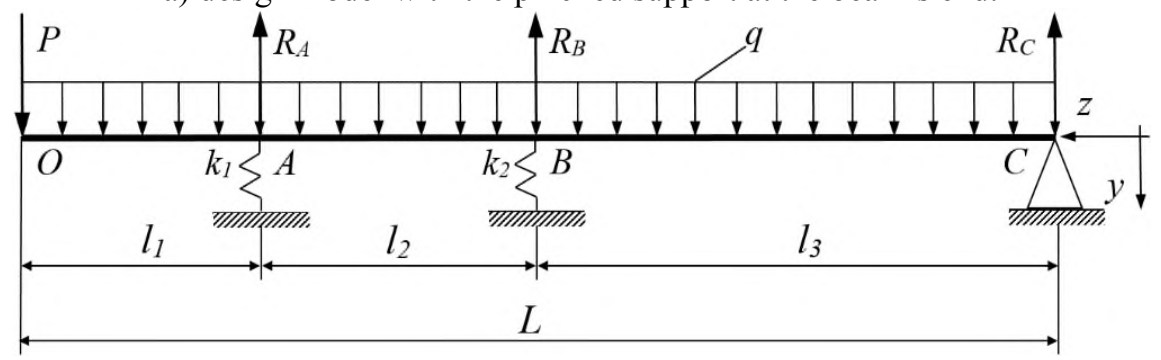

b) a design model with a hinge-fixed support at the beam`s end.

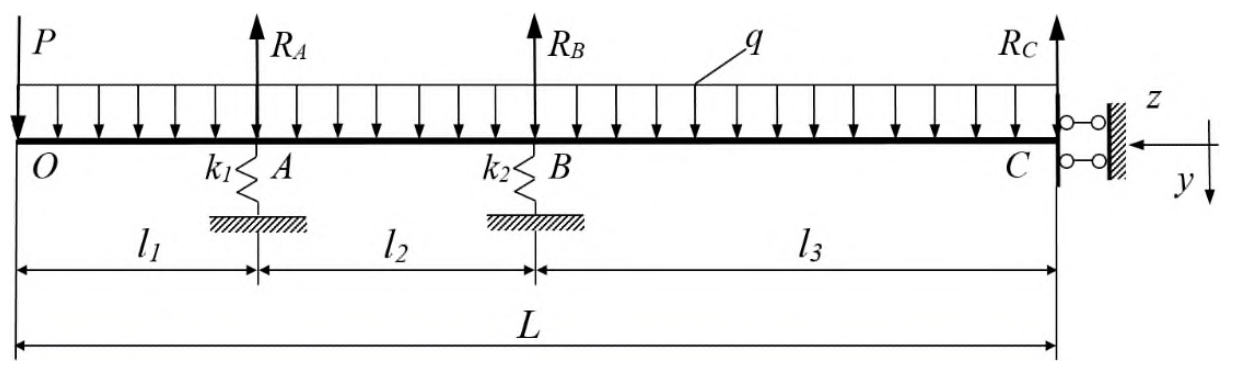

c) a design model with a sliding support at the beam`s end.

Fig. 1. Ship`s shafting line design diagram. 
To determine the beam`s deflection at the concentrated force application point, we will use the beam`s curved axis universal equation, written according to the initial parameters method [14]:

$$
V_{z}=V_{0}+\varphi_{0} z+\frac{1}{E] x}\left[\sum M \frac{(z-a)^{2}}{2 !}+\sum P \frac{(z-b)^{3}}{3 !}+\sum q \frac{(z-d)^{4}}{4 !}\right] \text {. }
$$

where: Vz - deflection of the beam`s arbitrary section; V0, $\varphi 0$ - initial parameters (deflection and section rotation angle at the origin); EJx - the beam 's bending stiffness; $a, b$, $\mathrm{d}$ - distances from the origin to sections, where external loads are applied; $\mathrm{z}$ - section's coordinate, the deflection of which is determined.

The essence of this method is that for a characteristic set of partial loads, the general integral of the deflection line differential equation is constructed as a set of corresponding particular solutions. Moreover, the deflection, rotation angle, the moment and the shear force are chosen as arbitrary constants at the origin of the common coordinate system. The solution is presented as general formula for an arbitrary $n$-th section of the bar, which is called an universal formula. We consider that with support sections $V_{i}$ downward positive motion, the reaction of the $i$-th elastic support $R_{i}$ is directed upwards and is equal to [5]:

$$
R_{\mathrm{i}}=-V_{\mathrm{i}} \times k_{\mathrm{i}}
$$

The pillar's boundary conditions at the beam`s end at $\mathrm{C}$ point are presented in table 1 .

Table 1. Boundary conditions at the beam's end at $\mathrm{C}$ point.

\begin{tabular}{|l|c|l|c|}
\hline \multirow{2}{*}{$\begin{array}{l}\text { Boundary condition } \\
\text { parameter }\end{array}$} & \multicolumn{2}{|l|}{ Kind of pillars at the beam`s end } \\
\cline { 2 - 4 } & Pinched & & Pinched \\
\hline Deflection & 0 & Deflection & 0 \\
\hline Rotation angle & 0 & Rotation angle & 0 \\
\hline Bending moment & $M_{c} \neq 0$ & Bending moment & $M_{c} \neq 0$ \\
\hline Shear force & $Q_{c} \neq 0$ & Shear force & $Q_{c} \neq 0$ \\
\hline
\end{tabular}

The written equation of deflections (2) in full form has six unknown parameters: deflection $V(0)$, angle of rotation of the section $\varphi(0)$, bending moment $M(0)$, transverse force $Q(0)$ at the origin, and two reactions on elastic supports $R_{A}, R_{B}$. Based on the boundary conditions, we compose a system of four homogeneous equations:

- for the design scheme shown in Figure 1 a:

$$
\left\{\begin{array}{c}
-V_{0}+\varphi_{0} L+\frac{1}{E J}\left[\frac{1}{6} R_{\mathrm{A}}\left(a_{2}+l_{\mathrm{a}}\right)^{3}+\frac{1}{6} R_{\mathrm{B}} l_{\mathrm{a}}^{\mathrm{a}}-\frac{1}{6} P L^{4}-\frac{1}{24} q L^{4}\right]=0 \\
-\varphi_{0}-\frac{1}{E J}\left[\frac{1}{2} R_{\mathrm{A}}\left(l_{2}+l_{\mathrm{a}}\right)^{2}+\frac{1}{2} R_{\mathrm{B}} l_{\mathrm{a}}^{2}-\frac{1}{2} P L^{2}-\frac{1}{6} q L^{\mathrm{a}}\right]=0 \\
-V_{0}+\varphi_{0} l_{1}+\frac{1}{E J}\left[-\frac{1}{6} P l_{1}^{3}-\frac{1}{24} q l_{1}^{4}\right]=-\frac{R_{A}}{k_{1}} \\
-V_{0}+\varphi_{0}\left(l_{1}+l_{2}\right)+\frac{1}{E J}\left[\frac{1}{6} R_{\mathrm{A}} l_{2}^{3}-\frac{1}{6} P\left(l_{1}+l_{2}\right)^{3}-\frac{1}{24} q\left(l_{1}+l_{2}\right)^{4}\right]=-\frac{R_{B}}{k_{2}}
\end{array}\right.
$$

- for the design scheme shown in Figure $1 \mathrm{~b}$ : 


$$
\left\{\begin{array}{c}
-V_{0}+\varphi_{0} L+\frac{1}{E J}\left[\frac{1}{6} R_{A}\left(l_{2}+l_{2}\right)^{\mathrm{a}}+\frac{1}{6} R_{\mathrm{B}} l_{\mathrm{a}}^{\mathrm{a}}-\frac{1}{6} P L^{4}-\frac{1}{24} q L^{4}\right]=0 \\
R_{\mathrm{A}}\left(l_{2}+l_{\mathrm{a}}\right)+R_{\mathrm{B}} l_{\mathrm{a}}-P L-q \frac{L^{2}}{2}=0 \\
-V_{0}+\varphi_{0} l_{1}+\frac{1}{E J}\left[-\frac{1}{6} P l_{1}^{\mathrm{a}}-\frac{1}{24} q l_{1}^{4}\right]=-\frac{R_{A}}{k_{1}} \\
-V_{0}+\varphi_{0}\left(l_{1}+l_{2}\right)+\frac{1}{E]}\left[\frac{1}{6} R_{\mathrm{A}} l_{2}^{3}-\frac{1}{6} P\left(l_{1}+l_{2}\right)^{\mathrm{a}}-\frac{1}{24} q\left(l_{1}+l_{2}\right)^{4}\right]=-\frac{R_{B}}{k_{2}}
\end{array}\right.
$$

- for the design scheme shown in Figure $1 \mathrm{c}$ :

$$
\left\{\begin{array}{c}
-\varphi_{0}-\frac{1}{E J}\left[\frac{1}{2} R_{A}\left(l_{2}+l_{\mathrm{a}}\right)^{2}+\frac{1}{2} R_{\mathrm{B}} l_{\mathrm{a}}^{2}-\frac{1}{2} P L^{2}-\frac{1}{6} q L^{\mathrm{a}}\right]=0 \\
R_{\mathrm{A}}+R_{\mathrm{B}}-P-q L=0 \\
-V_{0}+\varphi_{0} l_{1}+\frac{1}{E J}\left[-\frac{1}{6} P l_{1}^{3}-\frac{1}{24} q l_{1}^{4}\right]=-\frac{R_{A}}{k_{1}} \\
-V_{0}+\varphi_{0}\left(l_{1}+l_{2}\right)+\frac{1}{E l}\left[\frac{1}{6} R_{A} l_{2}^{3}-\frac{1}{6} P\left(l_{1}+l_{2}\right)^{\mathrm{a}}-\frac{1}{24} q\left(l_{1}+l_{2}\right)^{4}\right]=-\frac{R_{B}}{k_{2}}
\end{array}\right.
$$

\section{Results}

For a comparative analysis of the boundary conditions influence on the shafting line reliability, let us consider design schemes with numerical parameter values: beam diameter $d=120 \mathrm{~mm}$; screw weight $P=4100 \mathrm{~N}$; length of the entire shaft $L=3 \mathrm{~m}$; console length $l_{1}=0,5 \mathrm{~m}$; span length $l_{2}=m$; span length $l_{3}=m$; distributed load $q=870 \mathrm{~N} / \mathrm{m}$. The stiffness factor of two elastic supports varied in range from $1 \cdot 106 \mathrm{~N} / \mathrm{m}$ to $1 \cdot 1010 \mathrm{~N} / \mathrm{m}$. The calculation determined the values of the elastic supports reaction coefficient and the beam's deflection at the concentrated load point of action:

Table 2. Determination of reaction forces in supports and beam deflection under different boundary conditions.

\begin{tabular}{|c|c|c|c|c|c|c|}
\hline \multirow{2}{*}{$\begin{array}{c}\text { Design } \\
\text { model } \\
\text { parameters }\end{array}$} & $\begin{array}{c}\text { Design } \\
\text { scheme } \\
\text { option }\end{array}$ & \multicolumn{5}{|c|}{ Stiffness factor K, N/m } \\
\cline { 2 - 7 } & I & 4411,12 & $\mathrm{R}_{1}, \mathrm{~N}$ & I & 4411,12 & $\mathrm{R}_{1}, \mathrm{~N}$ \\
\hline \multirow{3}{*}{$\mathrm{R}_{1}, \mathrm{~N}$} & $\mathrm{II}$ & 5463,16 & & II & 5463,16 & \\
\cline { 2 - 7 } & III & 4624,58 & & III & 4624,58 & \\
\hline \multirow{3}{*}{$\mathrm{R}_{2}, \mathrm{~N}$} & $\mathrm{I}$ & 1103,04 & $\mathrm{R}_{2}, \mathrm{~N}$ & $\mathrm{I}$ & 1103,04 & $\mathrm{R}_{2}, \mathrm{~N}$ \\
\cline { 2 - 7 } & II & 2132,02 & & II & 2132,02 & \\
\cline { 2 - 7 } & III & 2056,18 & & III & 2056,18 & \\
\hline \multirow{3}{*}{$\mathrm{R}_{3}, \mathrm{~N}$} & $\mathrm{I}$ & 1166,6 & $\mathrm{R}_{3}, \mathrm{~N}$ & I & 1166,6 & $\mathrm{R}_{3}, \mathrm{~N}$ \\
\cline { 2 - 7 } & II & $-914,42$ & & II & $-914,42$ & \\
\cline { 2 - 7 } & III & 0 & & III & 0 & \\
\hline \multirow{3}{*}{$\mathrm{V}_{0}, \mathrm{~mm}$} & $\mathrm{I}$ & 6,12 & $\mathrm{~V}_{0}, \mathrm{~mm}$ & I & 6,12 & $\mathrm{~V}_{0}, \mathrm{~mm}$ \\
\cline { 2 - 7 } & II & 7,1 & & II & 7,1 & \\
\cline { 2 - 7 } & III & 6,03 & & III & 6,03 & \\
\hline
\end{tabular}

The transverse vibrations natural frequency expression with one degree of freedom, with respect to the beam's deflection from the load given, has the form [14]: 


$$
\omega=\sqrt{\frac{g}{V_{0}}}
$$

Lateral oscillations calculation allows you to check the ship's shafting supports location, the length and selection of stern tube bearings elastic properties, their number, as well as mass and dimensions of the propeller. The ship`s shafting line lateral vibrations natural frequency value is affected by deflection parameter $\mathrm{V} 0$ at the propeller's attachment point $[15,16]$. The greater deflection, the lower the shaft's linear (6) transverse vibrations natural frequency.

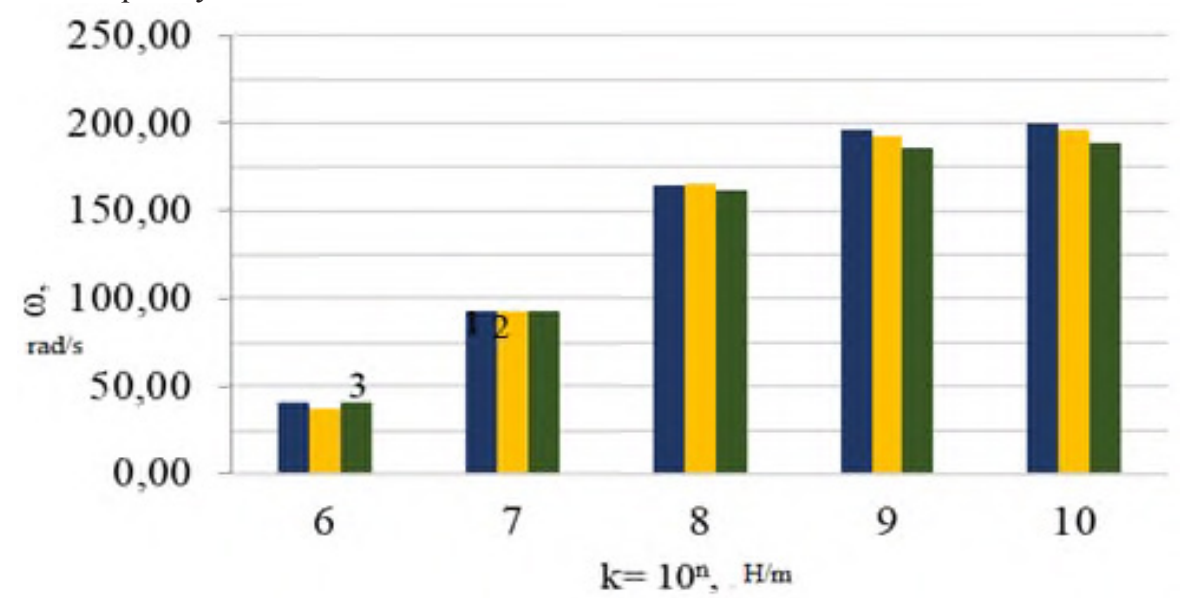

Fig. 2. Diagram of transverse vibrations natural frequency. 1 - Figure 1 a; 2- Figure 1 b; 3- Figure 1 c.

Based on the obtained results, it is possible to make a conclusion that fastening method has a significant effect on the shafting strength parameters. A rigidly terminated shaft has the highest natural frequency and the sliding bearing the lowest one. Stiffness factor decreasing doesn't affect much on the stern tube bearing stiffness, which depends on stern tube bearing bushings, as well as shaft line misalignment and transverse vibrations natural frequency don`t change significantly.

\section{Conclusion}

When designing ship shafting lines, it is considered that it's possible to use precisely the hinge support at the beam's end in the design scheme. This will increase the shafting line's and the entire ship power plant's strength parameters. The rigidity and resistance of the ship's shafting and its auxiliary elements to the action of dynamic and random loads on them increases. The results of the study will find application in the calculations of ship shafting for transverse and parametric vibrations.

\section{References}

1. A. Grządzielaa, T. Batu, Journal of marine engineering \& technology 16, 4 (2017)

2. R.J.O. de Waal, A. Bekker, P.S. Heyns, Data in Brief 19 (2018)

3. A. Halyavkin, I. Razov, V. Mamontov, G. Kushner, IOP Conference Series: Earth and Environmental Science 90 (2017) DOI: 10.1088/1755-1315/90/1/012078 
4. A.D. Pizzo, L.P. Di Noia, E. Fedele, A Energies 3420, 13 (2020)

5. Y. Huang, Z.X. Tian, R.C. Chen, H.Y. Cao, Mech. Mach. Theory 108 (2017)

6. Y.X. Huang, T.S. Wang, Y. Zhao, Composite Structures 20 (2018)

7. H.J. Yang, F. Lu, C.D. Che, Journal of Shanghai Jiao Tong University 6 (2018)

8. H.J. Yang, W.Z. Wang, J. Li, et al. Ship Building of China 1 (2018)

9. Y-H. Sun, Ch-Sh. Lin, W-D. Jia, G-J. Zhai, Progress in Electromagnetics Research M 52 (2016)

10. X.L. Zhang, Z.W. Yin, G.Y. Gao, et al. Tribology International 85 (2015)

11. E. Grebe, D.V. Loshadkin, G.A. Kushner, A.A. Haljavkin, A.A. Dudanov, Proceedings of 19th International Marine Industries Conference (MIC 2017)

12. H. Yin, J. Liu, F. Zeng, Journal of Vibroengineering 22 (2020)

13. K. Boonlong, P. Jeenkour, Vibroengineering procedia 16 (2017)

14. A. Grządziela, J. Musiał, Ł. Muślewski, M. Pająk, Polish maritime research 1(85), 22 (2015)

15. B. Avdeev, A. Vyngra, S. Chernyi, Improving the Electricity Quality by Means of a Single-Phase Solid-State Transformer, Designs 4(3), $35 \quad$ (2020) doi: 10.3390/designs4030035

16. Q. Wu, Y. Gu, Y. Li, B. Zhang, S. Chepinskiy, J. Wang, et al. Position Control of Cable-Driven Robotic Soft Arm Based on Deep Reinforcement Learning. Information 11(6), 310 (2020) doi: 10.3390/info11060310

17. Z. Liu, W. Li, H. Ouyang, Shock and Vibration 2016 (2016) 